\title{
HIGH-PERFORMANCE THIN-LAYER CHROMATOGRAPHY ASSAY FOR EPOXIDE HYDROLASE ACTIVITY AND THE DETERMINATION OF PHENOXYPROPANE-1,2-DIOLS
}

\section{E. VAN DEN EECKHOUT* and P. DE MOERLOOSE}

State University of Ghent, Faculty of Pharmaceutical Sciences, Department of Pharmaceutical Chemistry and Drug Quality Control. Harelbekestraat 72, B-9000 Ghent (Belgium)

and

\section{J. E. SINSHEIMER}

University of Michigan, College of Pharmacy, Ann Arbor, MI 48109 (U.S.A.)

(Received September 17th, 1984)

\section{SUMMARY}

A simple, rapid and sensitive high-performance thin-layer chromatographic assay for the determination of epoxide hydrolase activity in rat liver homogenates is described. It is extended to the determination of a series of phenoxypropane-1,2diols. The hydrolase assay has the advantages of using a readily available substrate, 2,3-epoxypropyl 4-methoxyphenyl ether, of multiple sample application, and of the simultaneous determination of reaction product (diol) as well as unchanged substrate (epoxide). The use of an internal standard, 4-nitroanisole, results in high sensitivity and good reproducibility of the proposed method. The limit of diol detection is 20 pmol.

\section{INTRODUCTION}

During the past two decades epoxides as such, or as metabolites from exogenous and endogenous compounds, have been the subject of many studies because of their potential mutagenic and/or carcinogenic properties $\mathbf{1 , 2}$.

Epoxides are known to be transformed by epoxide hydrolase, which catalyses the enzymatic hydration of epoxides to 1,2-diols.

We have been interested in the structure-toxicity relationship of aliphatic epoxides ${ }^{3}$. The phenyl glycidyl ethers (2,3-epoxypropyl phenyl ethers) were used as a series of compounds in which we studied substituent effects on their mutagenicity ${ }^{4}$. These compounds will be used in further studies as substrates for epoxide hydrolase, to complement mutagenicity with detoxification data. In order to be able to measure the enzymatic activity of different liver homogenates as sources for epoxide hydrolase, we needed a simple and rapid assay method.

Numerous methods for the determination of epoxide hydrolase activity already exist. Radiometric assays are the most widely used (ref. 5 , and references therein) but 
require the availability or the synthesis of radioactive substrates. High-performance liquid chromatographic (HPLC) methods certainly have the required sensitivity and reproducibility ${ }^{6 \rightarrow} \rightarrow$, but are time- and solvent-consuming. Other techniques, such as fluorimetry, although very sensitive ${ }^{10}$, cause quenching at higher substrate concentrations, or were designed for special purposes ${ }^{11}$. Gas chromatography ${ }^{12-14}$ requires derivatization, and immunoassay methods are designed for purified epoxide hydrolases ${ }^{15,16}$.

The proposed high-performance thin-layer chromatographic (HPTLC) method determines the reaction product 3-(4-methoxyphenoxy)propane-1,2-diol (II), after extraction from an incubation mixture of 2,3-epoxypropyl 4-methoxyphenyl ether (I) in a rat homogenate:

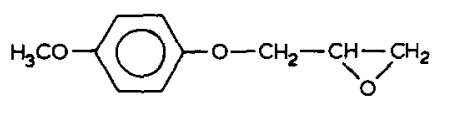

I

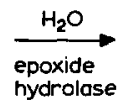

yorolase

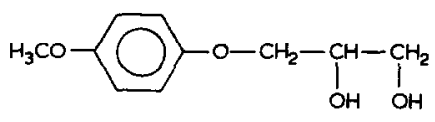

I

The HPTLC procedure described here has the advantage of handling large numbers of samples, without sacrificing reproducibility and sensitivity. The method is free from interference, even in crude homogenate fractions, and should form the basis for the analysis of the reactivity of related epoxides.

\section{EXPERIMENTAL}

\section{Materials}

All solvents used were reagent grade. 2,3-Epoxypropyl 4-methoxyphenyl ether, 2,3-epoxypropyl 4-chlorophenyl ether, 2,3-epoxypropyl phenyl ether, 2,3-epoxypropyl 4-tert.-butylphenyl ether, styrene glycol and 4-nitroanisole were obtained from Aldrich (Beerse, Belgium). 2,3-Epoxypropyl 4-nitrophenyl ether was obtained from Eastman Kodak (Rochester, NY, U.S.A.) 3-phenoxypropane-1,2-diol, 3-(4-chlorophenoxy)propane-1,2-diol, 3-(4-tert.-butylphenoxy) propane-1,2-diol, 3-(4-nitrophenoxy)propane-1,2-diol were synthesized according to published procedures ${ }^{17}$ and purified by preparative TLC in hexane-ethyl acetate (3:7) as solvent. HPTLC silica gel 60 plates $(10 \times 10 \mathrm{~cm})$ without a fluorescence indicator $(E$. Merck, Darmstadt, F.R.G.) and phase-separating filter paper (Whatman $1 \mathrm{PS}, 9.0 \mathrm{~cm}$ ) were used.

\section{Apparatus}

The HPTLC plates were scanned with a Zeiss KM-3 chromatogram spectrophotometer in the reflectance mode for UV absorption, with a deuterium light source. Samples were spotted by means of an application system (Nanomat, Camag, Muttenz, Switzerland) with 200-nl fixed-volume platinum-iridium capillary pipettes, resulting in spot diameters of less than $2 \mathrm{~mm}$. Samples were spotted using the data pair technique, i.e. unknowns and standard solutions were spotted to give a pair for each concentration, with the two spots being about a half-plate width apart ${ }^{18}$. The HPTLC plates were developed in a twin-trough chamber (Camag). 


\section{Liver homogenate preparations (S-9)}

Homogenates were prepared according to Ames et al. ${ }^{19}$ from the liver of control male Wistar rats pretreated with an intraperitoneal injection of sodium phenobarbital $(80 \mathrm{mg} / \mathrm{kg}$ body weight for 5 days). On the sixth day the rats were killed by decapitation. Protein was measured by the Lowry method ${ }^{20}$ with bovine serum albumin as standard.

\section{Incubation procedure and extraction}

A typical incubation mixture consisted of $1 \mathrm{ml}$ of S-9 rat liver homogenate (30 $\mathrm{mg}$ protein per millilitre), $4 \mathrm{ml}$ of $0.066 \mathrm{M}$ phosphate buffer (pH 7.4) and $50 \mu \mathrm{l}$ of substrate: 2,3-epoxypropyl 4-methoxyphenyl ether $(10 \mathrm{mg} / \mathrm{ml}$ acetone). Prior to addition of the substrate, rat liver homogenates were equilibrated for $2 \mathrm{~min}$ at $37^{\circ} \mathrm{C}$. In the standard assay, incubations were carried out for $5 \mathrm{~min}$ at $37^{\circ} \mathrm{C}$. The incubations were stopped by putting the test-tubes in liquid nitrogen. Internal standard was added ( $50 \mu \mathrm{l}$ of a solution of $5 \mathrm{mg}$ of 4-nitroanisole per millilitre of acetone), and extraction was performed twice with $2 \mathrm{ml}$ of ethyl acetate. The ethyl acetate layers were collected and filtered over phase-separating filter paper. The solvent was evaporated under reduced pressure, and the residue was taken up in $100 \mu \mathrm{l}$ of methanol. This solution $(200 \mathrm{nl})$ was spotted on an HPTLC plate, developed and scanned as further described.

\section{Choice of internal standard and chromatographic conditions}

To develop the method, styrene glycol $(75 \mathrm{mg} / \mathrm{ml}$ acetone) was first used as an internal standard. Separation between diol II and styrene glycol was obtained with hexane-ethyl acetate (3:7), at room temperature. In the final method, 4-nitroanisole was used as internal standard. Separation among the diol, internal standard and remaining epoxide could not be obtained with the former solvent system, but was achieved with hexane-ethyl acetate (7:3) developed twice at $10^{\circ} \mathrm{C}$. The HPTLC plates were developed over a height of $5.0 \mathrm{~cm}$. After development, the plates were dried under a stream of nitrogen, and were then ready for scanning without further processing.

\section{Quantitation of HPTLC spots}

With styrene glycol as internal standard, the scanning wavelength was $265 \mathrm{~nm}$, and with 4-nitroanisole it was $280 \mathrm{~nm}$. The slit width was $3.5 \times 0.1 \mathrm{~mm}$, the scanning speed was $50 \mathrm{~mm} / \mathrm{min}$. Peak heights were measured manually. The concentration of 3-(4-methoxyphenoxy)propane-1,2-diol was calculated from calibration graphs constructed by plotting the peak height ratios (diol to internal standard) versus the amount of diol in the reference spot. In the final method, with 4-nitroanisole as internal standard, the concentration of the remaining 2,3-epoxypropyl 4-methoxyphenyl ether was also calculated from calibration graphs constructed by plotting the peak height ratios (epoxide to internal standard) versus the amount of epoxide in the reference spot. Each point on the calibration graphs was the mean of three determinations. All calibration graphs were linear in the concentration ranges used.

\section{Standard curve}

Standard curves were obtained by adding $50 \mu \mathrm{l}$ of 3-(4-methoxypenoxy)-1,2propanediol (concentration range $2-10 \mathrm{mg} / \mathrm{ml}$ acetone), $50 \mu \mathrm{l}$ of 2,3-epoxypropyl 4- 
methoxyphenyl ether (concentration range $2-10 \mathrm{mg} / \mathrm{ml}$ acetone) and $50 \mu \mathrm{l}$ of styrene glycol $(75 \mathrm{mg} / \mathrm{ml}$ acetone) or 4-nitroanisole $(5 \mathrm{mg} / \mathrm{ml}$ acetone $)$ to $1.0 \mathrm{ml}$ of phosphate buffer ( $\mathrm{pH}$ 7.4). This was followed by extracting with $2 \times 2 \mathrm{ml}$ of ethyl acetate, as described for the incubation procedure, and by HPTLC, as described for chromatographic conditions and quantitation of HPTLC.

\section{UV spectra}

UV spectra were taken directly from the plate for 3-(4-methoxypenoxy)-1,2propane diol $(5 \mathrm{mg} / \mathrm{ml}$ acetone), for 3-(4-tert.-butylphenoxy)-1,2-propane diol (5 $\mathrm{mg} / \mathrm{ml}$ acetone), for 3-(4-nitrophenoxy)-1,2-propane diol ( $5 \mathrm{mg} / \mathrm{ml}$ acetone), for 3(4-chlorophenoxy)-1,2-propane diol and for styrene glycol $(25 \mathrm{mg} / \mathrm{ml}$ acetone), with $200 \mathrm{nl}$ volumes spotted and the solvent system hexane-ethyl acetate (3:7) used for development. For 4-nitroanisole $(3 \mathrm{mg} / \mathrm{ml}$ acetone), $200 \mathrm{nl}$ were spotted and the solvent hexane-ethyl acetate (7:3) was used.

\section{RESULTS AND DISCUSSION}

The choice of 2,3-epoxypropyl 4-methoxyphenyl ether as substrate was dictated by several considerations. Our main goal was the study of the detoxification processes of a series of phenoxypropane-1,2-diols. We were thus attracted by the use of either a number of compounds in this series or a single structurally closely related compound. Styrene oxide has been widely used as a substrate for epoxide hydrolase activity, but there are stability problems and the compound displays a low molecular absorptivity, which considerably reduces the sensitivity for UV measurements. 2,3Epoxypropyl 4-nitrophenyl ether has been successfully used in an HPLC determination of epoxide hydrolase activity by Giuliano $\mathrm{et}$ al. ${ }^{7}$ and should be especially applicable to HPTLC because of its increased molar absorptivity. However, 2,3epoxypropyl 4-methoxyphenyl ether and its reaction product 3-(4-methoxyphenoxy)-propane-1,2-diol were used in the present study as being more typical of the phenyl glycidyl ether series in their UV properties. These compounds are both stable and commercially available. The diol displays a maximum at $280 \mathrm{~nm}$, a wavelength sufficiently shifted from the far UV, to decrease the possibility of interference from natural occurring substances in liver homogenate fractions. While developing our method we used styrene glycol as an internal standard, as it is closely related to the reaction product. With the solvent system hexane-ethyl acetate (3:7), styrene glycol and 3-(4-methoxyphenoxy)propane-1,2-diol could be easily separated and measured (Table I). All the other phenoxypropane-1,2-diols tried were separated from styrene glycol (Table I), so the method could be extended to the determination of this whole series. However, the substrate 2,3-epoxypropyl 4-methoxyphenyl ether ran in the solvent front and thus could not be quantitated (Table I). Also, the UV spectrum of 3-(4-methoxyphenoxy)-1,2-propanediol displays a maximum at $280 \mathrm{~nm}$ on the TLC plate (versus $290 \mathrm{~nm}$ in methanolic solution), but styrene glycol has an extremely low absorptivity at $280 \mathrm{~nm}$, obliging us to work at $265 \mathrm{~nm}$, its maximum absorbance wavelength. As this decreased the sensitivity of the method, we looked for an internal standard that would allow us to work at $280 \mathrm{~nm}$. The choice was 4-nitroanisole, which displays a plate maximum of $305 \mathrm{~nm}$, but still has high absorbance at $280 \mathrm{~nm}$. However, with the solvent system hexane-ethyl acetate (3:7), 4-nitroanisole is not 


\section{TABLE I}

HPTLC OF A SERIES OF 2,3-EPOXYPROPYL ETHERS, CORRESPONDING DIOLS, STYRENE GLYCOL AND 4NITROANISOLE

Solvent I: hexane-ethyl acetate (30:70), room temperature; solvent II: hexane ethyl acetate (70:30), developed twice, $10^{\circ} \mathrm{C}$.

\begin{tabular}{lll}
\hline Compounds & \multicolumn{2}{l}{$\boldsymbol{R}_{\boldsymbol{F}}$ value } \\
\cline { 2 - 3 } & Solvent $I$ & Solvent II \\
\hline 2,3-Epoxypropyl phenyl ether & 0.90 & 0.77 \\
Phenoxypropane-1,2-diol & 0.37 & 0.08 \\
2,3-Epoxypropyl 4-methoxyphenyl ether & 0.90 & 0.66 \\
3-(4-Methoxyphenoxy)propane-1,2-diol & 0.29 & 0.10 \\
2,3-Epoxypropyl 4-nitrophenyl ether & 0.90 & 0.70 \\
3-(4-Nitrophenoxy)propane-1,2-diol & 0.16 & 0.10 \\
2,3-Epoxypropyl 4-chlorophenyl ether & 0.90 & 0.71 \\
3-(4-Chlorophenoxy)propane-1,2-diol & 0.29 & 0.09 \\
2,3-Epoxypropyl 4-tert.-butylphenyl ether & 0.95 & 0.83 \\
3-(4-tert.-butylphenoxy)propane-1,2- diol & 0.46 & 0.13 \\
4-Nitroanisole & 1.00 & 0.81 \\
Styrene glycol & 0.49 & - \\
\hline
\end{tabular}

separated well enough from the solvent front. The solvent was changed to hexaneethyl acetate $(7: 3)$ at $10^{\circ} \mathrm{C}$, which has the advantage of separating reaction product, substrate and internal standard (Table I). This permits the quantitation of the remaining epoxide and the reaction product in the same run, giving two independent measurements of epoxide hydrolase activity. The separation is temperature dependent. The $\boldsymbol{R}_{\boldsymbol{F}}$ values are higher at room temperature or at $35^{\circ} \mathrm{C}$ than at lower temperature, but give a poor separation between epoxide and 4-nitroanisole.

The sensitivity of the method is increased by a factor of two by working at 280 $\mathrm{nm}$, the detection limit being $0.02 \mathrm{mg} / \mathrm{ml}$ of 3-(4-methoxyphenoxy)-1,2-propanediol (or $4 \mathrm{ng}$ on the plate). The standard curves for unchanged epoxide and diol were obtained by extracting epoxide, diol and internal standard from phosphate buffer (pH 7.4). The recovery of this extraction from buffer was the same as the recovery of an extraction from the S-9 fraction. Standard curves for epoxide and diol were linear in the concentration range $0-10 \mathrm{mg} / \mathrm{ml}$. The influence of the incubation time on diol formation is shown in Fig. 1. Each point is the mean of four measurements for two different incubations. The curve is linear up to at least $6 \mathrm{~min}$ for both normal and induced liver preparations; we chose $5 \mathrm{~min}$ for our standard assay procedure. Increasing the substrate concentration from 10 to $20 \mathrm{mg} / \mathrm{ml}$ did not affect the diol formation after $5 \mathrm{~min}$, thus meeting the requirement that the enzyme is saturated by the substrate. Correction for nonenzymatic hydration of the epoxide was not necessary because no detectable diol was seen in boiled enzyme control incubations.

The method was used to determine the specific activity of epoxide hydrolase in rat liver homogenate fractions. Fig. $2 a$ and $2 b$ show the chromatograms obtained from induced and uninduced rats. For uninduced rats epoxide hydrolase activity was $24 \pm 1.20 \mathrm{nmol} / \mathrm{min} / \mathrm{mg}$, for induced rats it was $64 \pm 3.21 \mathrm{nmoles} / \mathrm{min} / \mathrm{mg}$ (mean of ten determinations). The overall precision of the method was $5.02 \%$. 


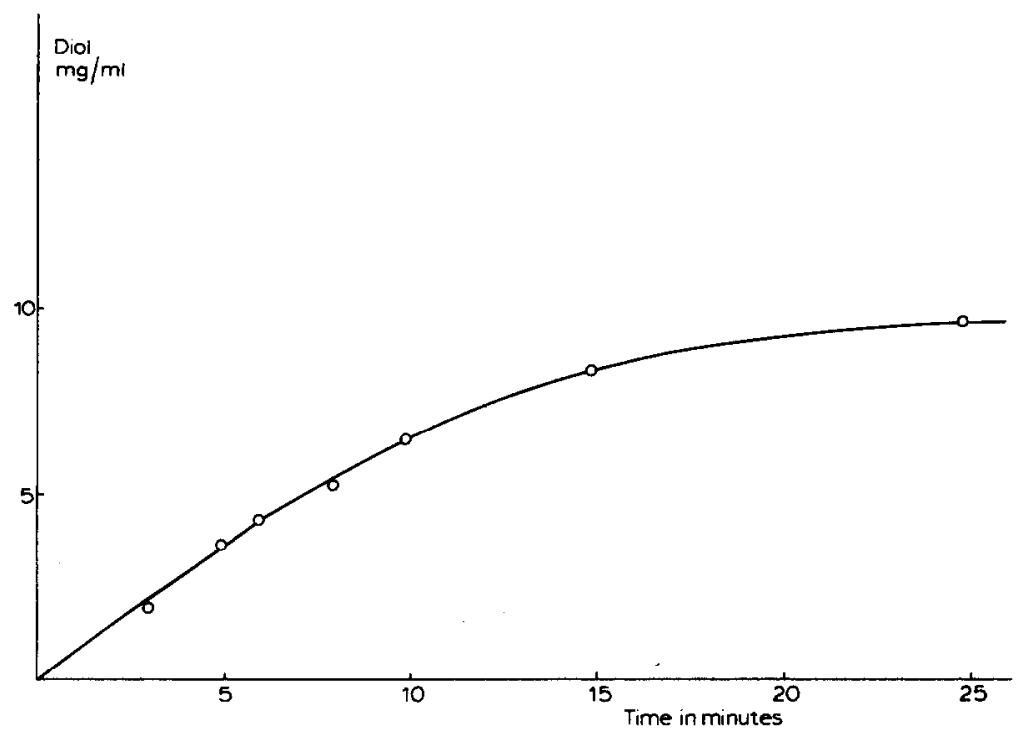

Fig. 1. Influence of incubation time on the formation of 3-(4-methoxyphenoxy)-1,2-propanediol.
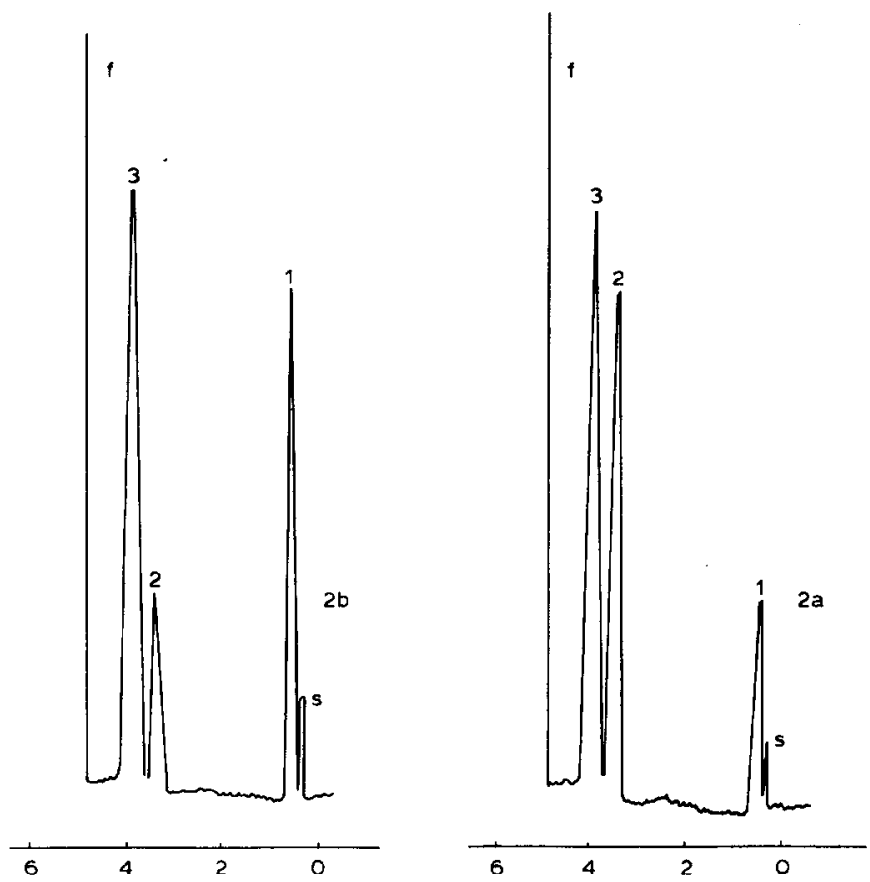

Fig. 2. HPTLC chromatogram of S-9 in incubation of 2,3-epoxypropyl 4-methoxyphenyl ether from (a) uninduced rats and (b) induced rats. Peaks: $1=3$-(4-methoxyphenoxy)-1,2-propanediol; 2 = 2,3-epoxypropyl 4-methoxyphenyl ether; $3=4$-nitroanisole; $s=$ start; $f=$ front. For experimental conditions see text. 
The remaining epoxide was also measured. This enabled us to check the validity of our results. For each run, the concentration of diol formed and remaining epoxide equals the original concentration of epoxide. This check also shows that under the conditions used, the epoxide is transformed only by epoxide hydrolase and not through another metabolic pathway.

The proposed HPTLC method was employed with other phenyl glycidyl ethers and their diols. Table I shows the results, which indicate the usefulness of the method for monitoring the phenyl glycidyl ether series as substrates for epoxide hydrolase.

\section{CONCLUSION}

The proposed HPTLC method, using a commercially available epoxide of the phenyl glycidyl ether series, is well suited for the rapid determination of epoxide hydrolase activity in liver homogenate fractions. It is sensitive and reproducible, with a coefficient of variation of $5.02 \%$. The method is free from interferences even in crude liver homogenate fractions, so it could be applied to cleaner samples such as microsomal or cytosolic liver fractions. This HPTLC method could perhaps also serve as the basis for developing methods to monitor the formation of diols from structurally related epoxides.

The method requires very small solvent amounts $(5 \mathrm{ml}$ per plate). Spotting, developing and scanning a plate of 18 samples requires $c a .1 \mathrm{~h}$. This is one fifth of the time required for existing HPLC methods ${ }^{6-9}$.

\section{ACKNOWLEDGEMENT}

JES acknowledges support by Grant Number 9R01ES03345-04Al awarded by the National Institute of Environmental Health Sciences.

\section{REFERENCES}

1 L. Ehrenberg and S. Hussein, Mutation Res., 31 (1975) 347.

2 M. M. Manson, Brit. J. Ind. Med., 37 (1980) 317.

3 D. R. Wade, S. C. Airy and J. E. Sinsheimer, Mutation Res., 58 (1978) 217.

4 S. H. Neau, B. H. Hooberman, S. W. Frantz and J. E. Sinsheimer, Mutation Res., 93 (1982) 297.

5 S. S. Gill, K. Ota and B. D. Hammock, Anal. Biochem., 131 (1983) 273.

6 R. B. Westkaemper and R. P. Hanzlik, Anal. Biochem., 102 (1980) 63.

7 K. A. Giuliano, E. P. Lau and R. R. Fall, J. Chromatogr., 202 (1980) 447.

8 M. S. F. Ross, D. S. Lines, K. R. Brain and R. G. Stevens, Anal. Biochem., 87 (1978) 267.

9 S. Mesnow and C. Heidelberger, Anal. Biochem., 67 (1975) 525.

10 P. M. Dansette, G. C. Dubois and D. M. Jerina, Anal. Biochem., 97 (1979) 340.

11 M. W. Hukkelhoven, E. W. Vromans, A. J. Vermorken and H. Bloemendaal, FEBS Lett., 144 (1982) 104.

12 M. Duverger-VanBogaert, G. Noël, B. Rollman, J. Cumps, M. Roberfroid and M. Mercier, Biochim. Biophys. Acta, 526 (1978) 77.

13 G. Belvedere, J. Pacheka, L. Cantoni, E. Mussini and M. Salmona, J. Chromatogr., 118 (1976) 387.

14 A. C. C. Craven, C. H. Walker and I. M. Murray-Lyon, Biochem. Pharmacol.,, 31 (1982) 1321.

15 S. S. Gill, S. I. Wie, T. M. Guenther, F. Oesch and B. D. Hammock, Carcinogenesis, 3 (1982) 1307.

16 C. B. Pickett, R. L. Jeter, J. Morrin and A. Y. H. Lu, J. Biol. Chem., 256 (1981) 8815.

17 P. Sims, Biochem. J., 131 (1973) 405.

18 H. Bethke, W. Santi and R. W. Frei, J. Chromatogr. Sci., 12 (1974) 392.

19 B. N. Ames, J. McCann and E. Yamasaki, Mutation Res., 31 (1975) 347.

20 O. H. Lowry, N. J. Rosebrough, A. L. Farr and R. J. Randall, J. Biol. Chem., 193 (1951) 265. 